\title{
The cost of diabetes in Latin America and the Caribbean in 2015: Evidence for decision and policy makers
}

\author{
Alberto Barcelo ${ }^{1}$, \\ Armando Arredondo ${ }^{2}$, \\ Amparo Gordillo-Tobar ${ }^{3}$, \\ Johanna Segovia ${ }^{1}$, \\ Anthony Qiang ${ }^{4}$ \\ ${ }^{1}$ University of Miami, Miller School of \\ Medicine, Miami, Florida, USA \\ ${ }^{2}$ National Institute of Public Health, \\ Cuernavaca, Mexico \\ ${ }^{3}$ World Bank, Washington D.C., USA \\ ${ }^{4}$ McMaster University, Hamilton, Canada
}

\section{Correspondence to:}

Armando Arredondo

National Institute of Public Health

Av. Universidad 655

Cuernavaca, México

Phone-Fax: 00527773293062

Email: armando.arredondo@insp.mx
Background The financial implications of the increase in the prevalence of diabetes in middle-income countries represents one of the main challenges to health system financing and to the society as a whole. The objective of this study was to estimate the economic cost of diabetes in Latin America and the Caribbean (LAC) in 2015.

Methods The study used a prevalence-based approach to estimate the direct and indirect costs related to diabetes in 29 LAC countries in 2015. Direct costs included health care expenditures such as medications (insulin and oral hypoglycemic agents), tests, consultations, hospitalizations, emergency visits and treating complications. Two different scenarios (S1 and S2) were used to analyze direct cost. S1 assumed conservative estimates while S2 assumed broader coverage of medication and services. Indirect costs included lost resources due to premature mortality, temporary and permanent disabilities.

Results In 2015 over 41 million adults (20 years of age and more) were estimated to have Diabetes Mellitus in LAC. The total indirect cost attributed to Diabetes was US $\$ 57.1$ billion, of which US $\$ 27.5$ billion was due to premature mortality, US $\$ 16.2$ billion to permanent disability, and US\$13.3 billion to temporary disability. The total direct cost was estimated between US $\$ 45$ and US $\$ 66$ billion, of which the highest estimated cost was due to treatment of complications (US\$ 1616 to US $\$ 26$ billion). Other estimates indicated the cost of insulin between US\$ 6 and US\$ 11 billion; oral medication US\$ 4 to US\$ 6 billion; consultations between US\$ 5 and US\$ 6 billion; hospitalization US\$ 10 billion; emergency visits US\$ 1 billion; test and laboratory exams between US\$ 1 and US\$ 3 million. The total cost of diabetes in 2015 in LAC was estimated to be between US $\$ 102$ and US $\$ 123$ billion. On average, the annual cost of treating one case of diabetes mellitus (DM) in LAC was estimated between US\$1088 and US\$ 1818. Per capita National Health Expenditures averaged US\$ 1061 in LAC.

Conclusions Diabetes represented a major economic burden to the countries of Latin America and the Caribbean in 2015. The estimates presented here are key information for decision-making that can be used in the formulation of policies and programs to achieve greater efficiency and effectiveness in the use of resources for diabetes prevention in the 29 countries of LAC. 
The cost of diabetes mellitus (DM) was estimated at US\$ 65 billion in 2000 in Latin America and the Caribbean (LAC) [1]. This burden was attributed to lost productivity due to mortality and disability, as well as direct medical costs caused by treating diabetes and its long-term complications.

The financial implications of the increase in the prevalence of diabetes in middle-income countries, represents one of the main challenges to be solved by health systems and society as a whole. DM is one of the top global public health concerns because of the increased morbidity and mortality among affected individuals. An estimated 415 million people suffer from diabetes globally in 2015 and this number is expected to reach the 642 million mark by 2040 [2]. This will increase direct health expenses as well as premature deaths and disability to unprecedented levels unless effective preventive and control strategies are implemented.

DM presents a global public health challenge, particularly among middle and low-income countries, where $80 \%$ of those with the disease live. Diabetes management is complex because it demands continuous care involving many services, tests, and medications, owing to the detrimental effect of chronic hyperglycemia on organs and tissues.

According to the 2012 World Health Organization (WHO) National Capacity Survey for Non Communicable Diseases (NCD) Prevention and Control, 95\% of countries in the Americas reported having DM policies or action plans. However, the capacity to prevent and control diabetes may be limited. In fact, only one third of the countries reported having operational evidence-based guidelines or protocols [3]. Population-based surveys and clinical series from many of the countries of LAC indicated that most people with diagnosed DM do not achieve treatment goals [4-9], increasing the risk of premature mortality and disabilities.

The objective of this study was to estimate the economic cost of diabetes in LAC in 2015. This study intends to update a previous estimate of the cost of diabetes in LAC for 2000 [1].

\section{METHODS}

This study used a prevalence-based approach that includes direct and indirect costs caused by diabetes. Adult (20 and more years of age) diabetes prevalence data for 2015 were used to estimate the direct and indirect costs related to diabetes in 29 LAC countries (Latin America: Argentina, Bolivia, Brazil, Chile, Colombia, Costa Rica, Cuba, Dominican Republic, Ecuador, El Salvador, Guatemala, Honduras, Mexico, Nicaragua, Panama, Paraguay, Peru, Puerto Rico, Uruguay and Venezuela; English Caribbean: Bahamas, Barbados, Belize, Grenada, Guyana, Jamaica, Saint Lucia, Suriname and Trinidad \& Tobago). Estimates included people with both type 1 and type 2 diabetes. The protocol for this project was reviewed and approved by the Committee on Health Research of the National Council of Science and Technology of Mexico. Patient records information was anonymized and de-identified prior to analysis.

\section{Data}

Direct costs included insulin and oral hypoglycemic agents, consultations, Alc tests, lipid profiles, micro albuminuria test, hospitalizations, emergency visits and treating complications. A "bottom-up" approach was used for direct cost estimation.

Indirect costs included lost resources due to mortality, as well as temporary and permanent disabilities. These were estimated using the human capital approach, which applies the present value of future earnings to estimate the burden of mortality and disability [10].

LAC demographic data for 2015 [11] were combined with prevalence data for 2015 from the International Diabetes Federation (IDF) to estimate the population with diabetes by age and gender for each country. Countries were classified using the World Bank GDP per capita classification [12] in low-income countries (US\$ 1035 or less), lower middle-income countries (US $\$ 1036$ to US\$4085), upper middleincome countries (US\$ 4086 to US\$12 615), and high-income countries (US\$ 12616 or more) [13]. The most recent National Health Expenditures (NHE) for each country were obtained from the Pan American Health Organization (PAHO) basic data indicators [14]. NHE for Puerto Rico was not available.

Five sources of original country data were used to produce estimates:

1. Commercial prices reported to the NCD Management National Capacity survey for chronic diseases in LAC [15] were obtained for tests, medications, and medical services. Prices were updated in 2015 by 
contacting health professionals and diabetes associations in each country. The PAHO database contains prices for insulin, oral medication, testing and services for 26 out of the 29 countries [15]. When a specific price for one country was not available we used an average price for countries of the same sub region (English Caribbean, Central or South America). The price list is available in Online Supplementary Document.

2. The Sentinel Surveillance (ViCen) questionnaire was completed for a random sample of 1899 patients in clinics in six countries (Bolivia, Chile, El Salvador, Guatemala, Honduras and Nicaragua). This survey explored health care utilization along with the presence of DM and diabetes-related long-term complications. The ViCen questionnaire was produced by PAHO in collaboration with the IDF and was used in previous research in Brazil [16,17].

3. A clinical record database of 51795 patients from Chile was used to calculate the prevalence of chronic complications (retinopathy, nephropathy, cardiovascular disease, neuropathy and peripheral vascular disease) [18]. This database was also used to produce estimates of permanent disability by age and sex adjusted by diabetes duration.

4. A database from the National Institute of Public Health (NIPH) in Mexico was used to estimate the cost of cases with and without long-term diabetes complications. The NIPH database provided an estimation of how much higher was the cost of cases with each long-term diabetes complication as compared to treating cases without complications [19].

5. The Barbados Eye Study (BES) is a cohort study funded by the National Eye Institute. It is a nationally representative cohort of 4709 Barbados-born citizens, ages 40 to 84 years and selected by simple random sampling. BES used Relative Risk Ratios (RR), based on the hazard ratios estimated from the Cox Proportional Hazard Model. RR was calculated comparing mortality for people with and without diabetes by age and gender using 9-year follow-up data (1997-2002) [20].

\section{Direct costs}

Two analyses were conducted separately to calculate direct cost. These analyses are identified as Scenario 1 (S1) and Scenario 2 (S2). S1 and S2 differ in estimations for the use of medication and the cost increase related to treatment of diabetes chronic complications. S1 contains conservative estimates while S2 assumes broader coverage of medication and services. Assumptions for S1 and S2 are described below. A sensitivity analysis was conducted to compare results of the cost for S1 and S2.

\section{Medication}

Insulin. The annual total cost of insulin (TCI) for the 29 LAC countries was estimated as follows:

$$
\mathrm{TCI}=\mathrm{NIU} \times \mathrm{CI} \times \mathrm{IC}(1)
$$

where NIU is the number of insulin users, $\mathrm{CI}$ is the cost of insulin per unit in each country, and IC is the number of insulin unit consumption per year.

Patterns of insulin use might be different in each country. Population based research indicated that among people with diabetes insulin use ranged from 2\% in Chile [4] and 29\% in Costa RicaRica [7]. Due to the paucity of information regarding the heterogeneity in the use of insulin use, we estimated two different proportion of insulin use: 10\% (S1) and 20\% (S2) of the diabetes population of each country.

Insulin consumption was assumed at $10000 \mathrm{IU}$ per person per year, as previously used by Phillips and Salmeron [21] and used in our previous analysis also [1]. The commercial cost of insulin in each country was taken from the PAHO database price list [15].

Oral hypoglycemic agents. The annual total cost of oral medications (TCO) for the 29 countries studied was estimated as follows.

$$
\mathrm{TCO}=\mathrm{NOU} \times \mathrm{CO} \times \mathrm{OC}(2)
$$

where NOU is the number of oral medication users, $\mathrm{CO}$ is the cost of oral medications (metformin) in each country extracted from the PAHO database, and $\mathrm{OC}$ is the estimated number of pills consumed per person each year.

The proportion of people taking oral medication varies from 90\% in Cuba [22] to 50\% in Belize [7]. As the proportion of people with diabetes taking oral medication might vary among countries two different 
assumptions were applied. We assumed that $50 \%$ or $80 \%$ of people with diabetes were taking oral medication for S1 and S2, respectively. The per capita consumption of metformin each year was estimated at 1500 tablets. Prices of Metformin 800 mg were taken from the PAHO database [15].

\section{Consultations and hospitalizations}

The total number of consultations and hospitalizations in the general population of each country was obtained from the PAHO basic indicator database [14]. These consultations and hospitalizations were considered to be due to general causes not related to diabetes.

The ViCen survey showed that people with diabetes made 3.5 times more medical visits and had 7 times more hospitalizations than people without diabetes [16]. In addition, the ViCen study showed that length of stay for those with diabetes was 1.9 days longer than those without diabetes [16]. The numbers of medical visits and hospitalization per inhabitants in each country were multiplied by factors of 2.55 and 6 , respectively, which represented the excess number of visits and hospitalizations due to diabetes $[6,7]$. The estimated number of people with diabetes was then multiplied by these products. In the case of hospitalizations, we obtained the total number of hospital days by multiplying the number by the average of length of stay in each country reported to the PAHO basic indicator database [14], and then increased by the fraction of 0.9 which was the excess number of days attributed to diabetes reported by patients to the ViCen study [16]. The costs of consultations and per-day hospitalization were obtained from PAHO's price list [15]. The cost of services, procedures or treatment was not included due to the paucity in country-specific data.

The annual total cost of consultations (TCC) was estimated as follows:

$$
\mathrm{TCC}=[(\mathrm{NC} \times \mathrm{CC}) \times \mathrm{COC}] \times \mathrm{DM}(4)
$$

where $\mathrm{NC}$ is the number of consultations per year, $\mathrm{CC}$ is the average cost of a general medicine consultation in each country, COC is the average cost of a consultation with an ophthalmologist in each country, and DM is the number of people under care. It was assumed that, across the region, 55\% of those with DM were treated by a health care providers.

The annual total cost of hospitalizations $(\mathrm{TCH})$ was estimated as follows:

$$
\mathrm{TCH}=\mathrm{NH} \times \mathrm{LH} \times \mathrm{CH} \times \mathrm{DM}(5)
$$

where $\mathrm{NH}$ is the annual number of hospitalizations, $\mathrm{LH}$ is the length of stay, $\mathrm{CH}$ is the average cost of a hospitalization, and DM is the number of those with diabetes who were at risk of being hospitalized. It was assumed that the total number of those with DM was at risk of being hospitalized.

The costs of hospitalizations related to DM and for general causes were calculated separately. Only the excess cost attributed to DM was included in the direct cost calculation. The cost of one day hospital stay was taken from the PAHO's price list [15]. This cost does not include any service or procedure. This cost is assumed to be conservative since it is well known that most cases of diabetes would require specific services and specialized care which are usually more expensive.

The average cost of a general and ophthalmologist medical visit per country was taken from the PAHO database [15].

The cost of medical visits related to DM and for general causes were calculated separately; only the excess cost estimated for those consultations attributed to DM was included in the direct cost calculation. The cost of consultation to a general practitioner in each country was taken from PAHO's price list [15] and was used as a proxy for all DM medical consultations because country specific prices for specialist visits (except for ophthalmologist) were not available. This cost does not include any additional procedures, it includes only a consultation with a physician.

\section{Testing}

The annual total cost of examinations (TCE) for the 29 countries was estimated as follows:

$$
\mathrm{TCE}=(\mathrm{Alc} \times \text { Lipid }+\mathrm{EKG}+\mathrm{Rx}+\text { Protein }) \times \mathrm{DM}(3)
$$

where Alc is the cost of a glycated hemoglobin test, Lipid is the cost of a lipid profile, EKG is the cost of an electrocardiogram, $\mathrm{Rx}$ is the cost of a chest $\mathrm{x}$-ray, protein is the cost of a urine protein test, and DM is the total population with diabetes. 
It was assumed that each person with DM was tested once a year with lipid profile, one electrocardiogram, one chest $\mathrm{x}$-ray, and one urine protein test. The number of Alc test was assumed to be 1 per year for S1 and 3 per year for S2.

\section{Emergency visits}

The annual total cost of emergency visits (TCEV) was estimated as follows:

$$
\mathrm{TCEV}=\mathrm{NEC} \times \mathrm{CEV} \times \mathrm{DM}(6)
$$

where NEC is the average annual number of emergency visits, CEV is the average cost of an emergency visit in each country taken from the PAHO price list, and DM is the total number of people with diabetes in each country.

The ViCent survey showed that those with diabetes made 1.4 emergency visit per year while those without diabetes reported 0.9 visits per year [16]. The estimated number of people with diabetes was multiplied by 1.4 to estimate the number of emergency visit. The cost of an emergency department visit in each country was obtained from the PAHO's price list [15].

The emergency cost does not include the cost of any procedure, it includes only the cost of being seen by a physician in an emergency department. The cost of emergency visits due to general causes was discounted. Only emergency visits attributed to diabetes ( 0.5 per person per year) were included.

\section{Complications}

This study included the cost of the following complications: cardiovascular disease, nephropathy, neuropathy, peripheral vascular disease and retinopathy. It also included the costs of dialysis, hemodialysis, photocoagulation and treating foot-related problems.

Three steps were used to estimate the cost of complications. First, the weighted probability of major complications from the Chilean QUALIDIAB [18] database were applied to the diabetes population to obtain the number of persons with each complication per country. Second, we estimated the cost of regular care for uncomplicated cases of DM for each country. We made different assumptions for regular care for S1 and S2. Population based surveys showed wide variation in the proportion of cases of diabetes under care in different countries. Therefore, we made different assumptions for the two scenarios. For S1 regular care for uncomplicated cases one visit to an ophthalmologist, one Alc, one lipid profile, one urine protein test, one electrocardiogram and one chest $\mathrm{x}$-ray for $55 \%$ of the population with diabetes. This was a conservative estimate that was based on protocols available in some of the participating countries. For S2 regular care for uncomplicated cases included one visit to an ophthalmologist, three Alc, one lipid profile, one urine protein test, one electrocardiogram and one chest $\mathrm{x}$-ray for $85 \%$ of the population with diabetes.

Available data from Chile [1], Brazil [17], and Mexico [19] showed that the ratio of expenditure per person with diabetes and chronic complications to persons with diabetes without complications was variable. Because of the heterogeneity of health care provision and medical costs across countries, for each complication a lower (S1) and higher (S2) ratio was used to produce two separate estimates. Among the three sources, we selected the lowest estimated cost ratio (S1) and an average of the other two estimates (S2). The ratio used for these calculations were retinopathy 1.09 and 1.86; neuropathy 1.08 and 1.58 ; Peripheral Vascular Disease 1.06 and 1.81; Cardiovascular Disease 1.23 and 1.86; and Nephropathy 1.76 and 2.96 for S1 and S2 respectively.

Third, we applied the excess of cost of treating (consultations, medications and other procedures) for each complication as per S1 and S2 cost ratio using the cost estimates for uncomplicated cases in each country as per previous calculation.

The total cost of consultations for retinopathy (TCCR) was estimated as follows:

$$
\mathrm{TCCR}=[(\mathrm{NCR} \times \mathrm{CC})+\mathrm{COC}] \times \mathrm{DM} \times \mathrm{PVR}(7)
$$

where TCCR is the annual cost of consultations for those with diabetes retinopathy, NCR is the number of consultations per person with DM-related retinopathy, and PVR is the prevalence of retinopathy.

The total cost of consultations for other (TCCO) DM-related complications was estimated as follows:

$$
\mathrm{TCCO}=\sum_{i \in I}\left[\left(\mathrm{NCC}_{i} \times \mathrm{CC}\right)+\mathrm{COC}\right] \times \mathrm{DM} \times \mathrm{PV}_{i}
$$

where TCCO is the annual cost of consultations for those with DM and long-term complications other than retinopathy, NCC is the number of consultations per person with a DM-related complication other 
than retinopathy, PV is the prevalence of the complication, and $i$ represents the four complications studied, excluding retinopathy.

The total cost of consultations for complications (TCCC) of those with DM-related complications was estimated as follows:

$$
\mathrm{TCCC}=\mathrm{TCCR}+\mathrm{TCCO}(9) .
$$

The total cost of hospitalizations related to complication (TCHC) was estimated as follows:

$$
\mathrm{TCHC}=\sum_{i \in I} \mathrm{NHC}_{i} \times \mathrm{LHC}_{i} \times \mathrm{CH} \times \mathrm{DM} \times \mathrm{PV}_{i}(10)
$$

where TCHC is the annual cost of hospitalizations for those with DM-related complications, NHC is the number of hospitalizations by person with DM-related complications, LHC is the length of a patient's hospital stay, $\mathrm{CH}$ is the average cost of a hospitalization per person, $\mathrm{PV}$ is the prevalence of complications, and $i$ is the set of complications studied.

The used age-weighted probability for each long-term complication was 1.09 for retinopathy, 1.23 for CVD, 2.35 for nephropathy, 1.08 for neuropathy, and 3.35 for PVD [18].

\section{Indirect costs}

\section{Mortality costs}

Mortality costs were estimated by multiplying the number of DM-related deaths by age range and gender by the number of years of productive life lost (YPLL) for each age by the country GDP per capita. A three percent discount was applied.

The number of DM-related deaths was calculated by multiplying the number of deaths for all causes, by the population attributable-fraction (PAF), which was estimated as follows:

$$
\mathrm{PAF}=\mathrm{P}(\mathrm{RR}-1) / 1+[\mathrm{P}(\mathrm{RR}-1)](11)
$$

where $\mathrm{P}$ is the prevalence of $\mathrm{DM}$ and $\mathrm{RR}$ is the relative risk of death from the disease.

The Barbados Eye Study (BES) is a cohort study that includes RR obtained from the Barbados Eye Study, which contained information from a cohort of people with diabetes. The RR used were Men 40-49=3.4 $(1.2-9.3) ; 50-59=2.0(1.0-3.7) ; 60-64=3.2(2.2-4.7)$ and Women $40-49=2.8(1.2-6.4) ; 50-59=4.4$ (2.4-8.3); 60-64=2.3 (1.1-1.9) (19). YPLL were included for individuals dying between the ages of 40 and 64 years. Only deaths estimated to occur between the ages of 40 and 79 years of age were included. YPLL between the ages of 40 and 64 years of ages were calculated since the age of retiring was assumed to be 65 years of age. 95\%-Confidence intervals were calculated by applying lower and higher estimates for the OR of original BES data [19].

\section{Disability costs}

Permanent disability. The total proportion of people with disability was estimated at $4.2 \%$ of the total target population. After discounting cases considered to be related to general causes, we estimated that $3.2 \%$ of the target population was disable due to diabetes. Estimates for other diseases and diabetes related disability by age and gender were obtained by applying research results from Gomez de Moura et al [23] to Brazil's national statistics [24]. The probability of diabetes related disability by age and gender was applied to the Chilean database and adjusted throughout a logistic regression by diabetes duration and the presence of chronic diabetes complications that would prevent people to remain in the workforce. These complications were blindness, amputations, strokes and infarction. The age-and-gender specific estimates were multiplied by the number of people with diabetes by age and gender to obtain the number of disabled due to diabetes. We used these estimates to calculate the number of discounted years of productive life lost (YPLL) before the age of 65 years. Only one year of income lost per person was included. GNP per capita for each country was used as a proxy for lost productivity in 2015. The cost of permanent disability was estimated by multiplying the per capita GNP by the number of YPLL.

Temporary disability. Only absenteeism was included as cost of temporary disability. The lack of information on other aspects of temporary disability such as bed days due to illness or care takers and others were not included. Temporary disability costs were calculated by multiplying the number of economically active people with DM by age and gender between the ages of 20 and 64 years, by the number of days lost due to disability by national annual GDP per capita (divided by 365 ) as a proxy of potential in- 
come per day. The number of people that were economically active in each country was calculated by discounting the unemployed as per data published by the World Bank [12]. The number of lost productive days was calculated with data from the ViCen survey [16]. The estimated number of lost days for general causes not related to DM was subtracted from the total lost days. Thus, the number of lost days included were only the excess number attributed to DM.

All costs estimates are presented in 2015 US dollars (US\$).

95\%-CI for permanent/ temporary disability as well for indirect cost, were calculated by using bootstrap analysis with 1000 replications of age-and-gender specific estimates.

All analysis were performed using SPSS 24 (IBM Analytics, Armonk, New York, USA) and Stata 12 (StataCorp, College Station, Texas, USA).

\section{RESULTS}

Over 41 million people were estimated to have DM throughout LAC in 2015. From the total in LAC of those with DM, approximately 97\% lived in Latin America (Central-South America, Mexico and the Spanish Caribbean) and 2\% in the English Caribbean. Overall, among components of indirect cost, US\$27.5 billion was attributed to diabetes related premature mortality, US\$ 16.2 billion to permanent disability, and US\$13.3 billion to temporary disability. The total indirect cost was US\$ 57.2 (US\$ 54.9-60.4) billion (Table 1).

Table 2 presents estimates of the cost of medication as well as exams and consultations for scenario 1 (S1) and scenario 2 (S2). Overall 4 to 6 million people with diabetes were estimated to use insulin with an estimated cost between US\$ 6.9 to US\$ 11.6 billion. The number of oral medication users was estimated between 19.7 and 33.5 million with an estimated cost of US\$ 11 to US\$18 million. The total cost of medication was estimated to be between US\$ 11 to US\$ 18 million. This shows how sensitive is direct cost to coverage, in particular the number of insulin or oral medication users.

The total number of hospitalization (Table 3) was 36746 from which more than 18 thousand were estimated to be attributed to diabetes causing a burden of more than US $\$ 10$ billion. The estimated number of emergency visit was more than 95 thousand with an estimated cost of more than US\$ 1 billion.

Table 1. Data on those with diabetes mellitus (DM) and estimated indirect costs in Latin America and the Caribbean, 2015

\begin{tabular}{|c|c|c|c|}
\hline ITEM & LATIN AMERICA & Engush Caribbean & TOTAL \\
\hline Populations $20-79\left(\times 10^{3}\right)$ & 315188 & 2598 & 317786 \\
\hline Total No. of people with diabetes $\left(\times 10^{3}\right)$ & 41022 & 554 & 41576 \\
\hline \multicolumn{4}{|l|}{ Mortality: } \\
\hline No. of deaths & 1364376 & 22137 & 1386513 \\
\hline Deaths related to diabetes ( $40-64$ years) & 313205 & 4897 & 318102 \\
\hline YPLL & 2044418 & 30214 & 2074633 \\
\hline Cost $\left(\mathrm{US} \$ \times 10^{6}\right)$ & 27280 & 305 & 27585 \\
\hline $95 \%$ CI $\left(\mathrm{US} \$ \times 10^{6}\right)$ & $8066-47905$ & $90-570$ & $8157-48475$ \\
\hline \multicolumn{4}{|l|}{ Permanent disability: } \\
\hline Total No. of people with permanent disability & 1389057 & 17407 & 1406464 \\
\hline YPLL due to DM & 1016571 & 26557 & 1043128 \\
\hline Cost in 1 year $\left(\mathrm{US} \$ \times 10^{6}\right)$ & 15863 & 342 & 16205 \\
\hline $95 \% \mathrm{CI}\left(\mathrm{US} \$ \times 10^{6}\right)$ & $15115-16702$ & $316-517$ & $15450-17037$ \\
\hline \multicolumn{4}{|l|}{ Temporary disability: } \\
\hline Estimated DM employed population (20-64) & 31463016 & 409686 & 31872702 \\
\hline No. of days missed of work general causes & 665563904 & 8306850 & 673870754 \\
\hline No. of days missed of work due to DM & 309631903 & 3864491 & 313496394 \\
\hline YPLL & 847567 & 10588 & 858154 \\
\hline Cost $\left(\mathrm{US} \$ \times 10^{6}\right)$ & 13212 & 179 & 13391 \\
\hline $95 \% \mathrm{CI}\left(\mathrm{US} \$ \times 10^{6}\right)$ & $12773-13735$ & $170-191$ & $12944-13906$ \\
\hline Indirect cost $\left(\mathrm{US} \$ \times 10^{6}\right)$ & 56355 & 826 & 57181 \\
\hline $95 \%$ CI $\left(\mathrm{US} \$ \times 10^{6}\right)$ & $54045-59565$ & 799-992 & $54881-60411$ \\
\hline
\end{tabular}

YPLL - years of productive life lost; CI - confidence interval 
Table 2. Direct cost of diabetes mellitus (DM) by in Latin America and the Caribbean (LAC) sub-region, 2015

\begin{tabular}{|c|c|c|c|c|c|c|}
\hline \multirow[t]{2}{*}{ ITEM } & \multicolumn{2}{|c|}{ Latin America } & \multicolumn{2}{|c|}{ Engush Caribbean } & \multicolumn{2}{|c|}{ Total } \\
\hline & S1 & S2 & S1 & $\mathrm{S} 2$ & S1 & S2 \\
\hline \multicolumn{7}{|l|}{ Medication: } \\
\hline No. of insulin users $\left(\times 10^{3}\right)$ & 3869 & 6550 & 184 & 364 & 4054 & 6915 \\
\hline No. of oral medication users $\left(\times 10^{3}\right)$ & 18851 & 32046 & 898 & 1527 & 19749 & 33573 \\
\hline Cost of insulin $\left(\mathrm{US} \$ \times 10^{6}\right)$ & 6671 & 10971 & 324 & 640 & 6995 & 11611 \\
\hline Cost of oral medication (US $\$ \times 10^{6}$ ) & 3811 & 6479 & 218 & 370 & 4029 & 6849 \\
\hline Total cost of medication $\left(\right.$ US $\left.\$ \times 10^{6}\right)$ & 10482 & 17450 & 542 & 1010 & 11024 & 18460 \\
\hline Cost of exams (US $\left.\$ \times 10^{6}\right)$ & 1252 & 2584 & 128 & 274 & 1380 & 2859 \\
\hline \multicolumn{7}{|l|}{ Consultations: } \\
\hline Total no. consultations $\left(\times 10^{3}\right)$ & 266169 & 321546 & 13538 & 15605 & 279708 & 337151 \\
\hline DM related causes $\left(\times 10^{3}\right)$ & 101523 & 156899 & 3789 & 5856 & 105312 & 162755 \\
\hline Cost DM related causes $\left(\mathrm{US} \$ \times 10^{6}\right)$ & 4872 & 6536 & 196 & 270 & 5068 & 6806 \\
\hline
\end{tabular}

Table 3. Cost of hospitalizations and emergency visit among those with diabetes in Latin America and the Caribbean in 2015

\begin{tabular}{lrrr} 
litem & Latin America & Enelish Caribbean & \multicolumn{1}{c}{ Total } \\
Total No. of hospitalization $\left(\times 10^{3}\right)$ & 34747 & 1998 & 36746 \\
\hline Diabetes-related causes $\left(\times 10^{3}\right)$ & 17462 & 832 & 18294 \\
\hline Total days & 135834 & 7843 & 143677 \\
\hline No. days $($ DM related causes) & 66691 & 3177 & 69868 \\
\hline Cost DM related $\left(\mathrm{US} \$ \times 10^{6}\right)$ & 10025 & 309 & 10334 \\
\hline No. emergency visits & 91277 & 4349 & 95626 \\
\hline Cost $\left(\right.$ US $\left.\$ \times 10^{6}\right)$ & 1036 & 22 & 1059 \\
\hline
\end{tabular}

DM - diabetes mellitus

Table 4. Estimated number $\left(\times 10^{3}\right)$ of people with diabetes and chronic complications in Latin America and the Caribbean, 2015

\begin{tabular}{lccc} 
Complications & $\begin{array}{c}\text { Latin } \\
\text { America }\end{array}$ & $\begin{array}{c}\text { English } \\
\text { Caribiean }\end{array}$ & Total \\
No. person with retinopathy & 4671 & 223 & 4894 \\
\hline No. person with cardiovascular disease & 4496 & 214 & 4711 \\
\hline No. person with nephropathy & 2306 & 110 & 2416 \\
\hline No. person with neuropathy & 3421 & 163 & 3584 \\
\hline No. person with peripheral vascular disease & 2254 & 107 & 2362 \\
\hline
\end{tabular}
tween US\$ 1088 and US\$ 1818 . Countries of LAC expended in health an average of US\$1063, with the highest among reported by Cuba (US\$2280) and the lowest by Guyana (US\$ 361). On average, NHE were notably lower among low income countries (US\$ 508 per capita) and the highest among higher income countries (US\$ 1063). Average expending on diabetes was close to average NHE for S1 and notably higher for S2. On average, among lower-middle income countries, NHE (US\$508) was notably lower than the per capita cost of care for people with diabetes assuming either S1 (US\$1014) or S2 (US\$1832)

Table 5. The cost $\left(\mathrm{US} \$ \times 10^{6}\right)$ of diabetes complications in Latin America and the Caribbean, 2015

\begin{tabular}{lcccccc} 
Cost & \multicolumn{2}{c}{ LAtin AmErica } & \multicolumn{2}{c}{ Eneush CaribienN } & \multicolumn{2}{c}{ Total } \\
& S1 & S2 & S1 & S2 & S1 & S2 \\
\hline Cost of retinopathy & 3345 & 6097 & 166 & 347 & 3511 & 6444 \\
\hline Cost of cardiovascular disease & 5435 & 7870 & 235 & 396 & 5670 & 8266 \\
\hline Cost of nephropathy & 2755 & 4434 & 147 & 258 & 2902 & 4692 \\
\hline Cost of neuropathy & 2028 & 3560 & 107 & 208 & 2134 & 3768 \\
\hline Cost of peripheral vascular disease & 1949 & 3686 & 90 & 1891 & 2040 & 3418 \\
\hline Total cost of complications & 15511 & 25204 & 746 & 1384 & 16257 & 26588 \\
\hline
\end{tabular}

More than 4 million people with diabetes were estimated to have retinopathy and cardiovascular diseases respectively, while more than 3 million were estimated to have neuropathy and more than 2 million were estimated to suffer from nephropathy or peripheral vascular disease, respectively (Table 4).

Treating chronic complications caused an estimated burden between US\$16.2 and US\$ 26.5 billion for S1 and S2 respectively. Cardiovascular disease was the costliest complication with an estimated burden between US\$5.6 and US $\$ 8.2$ billion followed by retinopathy (US $\$ 3.5$ to US $\$ 6.4$ billion), nephropathy (US\$2.9 to US\$ 4.6 bilripheral vascular disease (US\$ 2 to US\$ 3.4 billion) (Table 5).

Among countries of LAC (Table 6) the highest direct cost was estimated for Brazil (between US\$ 17.5-US\$ 23.8 billion); while the lowest was estimated for Grenada (between US\$ 4.0-US\$ 6.6 billion). The highest per capita cost was estimated for Puerto Rico, US\$27644949 and the lowest for Peru US\$ 445-821 (S2).

On average, the annual cost of treating one case was belion), neuropathy (US\$2.1 to US\$ 3.7 billion) and pe然 
Table 6. Total and per capita direct cost of diabetes mellitus (DM) and national health expenditures by country and GDP group, Latin America and the Caribbean, 2015

\begin{tabular}{|c|c|c|c|c|c|}
\hline \multirow[t]{2}{*}{ LoWER-Midole InCome } & \multirow{2}{*}{$\begin{array}{l}\text { National Health } \\
\text { Expenditures (USS) }\end{array}$} & \multicolumn{2}{|c|}{ S1 (Lower) } & \multicolumn{2}{|c|}{ S2 (Higher) } \\
\hline & & $\begin{array}{c}\text { Direct costs } \\
\left(\text { US } \$ \times 10^{6}\right)\end{array}$ & $\begin{array}{c}\text { Per capita } \\
\text { costs (US\$) }\end{array}$ & $\begin{array}{c}\text { Direct costs } \\
\left(\mathrm{US} \$ \times 10^{6}\right)\end{array}$ & $\begin{array}{c}\text { Per capita costs } \\
\text { (US\$) }\end{array}$ \\
\hline Bolivia & 420 & 263.4 & 677 & 483.8 & 1244 \\
\hline El Salvador & 565 & 353.2 & 1084 & 665.0 & 2040 \\
\hline Guatemala & 462 & 1054.3 & 1385 & 1943.1 & 2552 \\
\hline Guyana & 361 & 26.9 & 540 & 44.9 & 901 \\
\hline Honduras & 428 & 464.4 & 1388 & 855.9 & 2559 \\
\hline Nicaragua & 445 & 301.1 & 1091 & 512.0 & 1856 \\
\hline Paraguay & 874 & 301.8 & 931 & 542.0 & 1673 \\
\hline Sub-total & $508 \dagger$ & 2765.1 & $1014 \dagger$ & 5046.7 & $1832 \dagger$ \\
\hline \multicolumn{6}{|c|}{ Upper-middle income: } \\
\hline Argentina & 862 & 1741.1 & 1010 & 3026.3 & 1756 \\
\hline Belize & 487 & 20.9 & 728 & 32.5 & 1133 \\
\hline Brazil & 1318 & 17492.5 & 1227 & 23825.7 & 1672 \\
\hline Colombia & 962 & 2928.3 & 961 & 5367.5 & 1761 \\
\hline Costa Rica & 1390 & 292.1 & 1047 & 521.6 & 1870 \\
\hline Cuba & 2280 & 562.4 & 551 & 937.7 & 919 \\
\hline Dominican Republic & 581 & 317.2 & 627 & 470.6 & 930 \\
\hline Ecuador & 1042 & 1144.8 & 1379 & 1753.1 & 2112 \\
\hline Grenada & 758 & 4.0 & 580 & 6.6 & 957 \\
\hline Jamaica & 476 & 311.7 & 1538 & 509.3 & 2513 \\
\hline Mexico & 1091 & 10659.1 & 930 & 14246.8 & 1243 \\
\hline Panama & 1678 & 361.7 & 1568 & 605.8 & 2627 \\
\hline Peru & 656 & 560.7 & 455 & 1010.7 & 821 \\
\hline Saint Lucia & 721 & 8.3 & 625 & 13.9 & 1044 \\
\hline Suriname & 947 & 26.2 & 625 & 41.9 & 1001 \\
\hline Venezuela & 950 & 1773.6 & 831 & 2865.3 & 1343 \\
\hline Sub-total & $1012 \dagger$ & 38204.6 & $918 \dagger$ & 55235.3 & $1481 \dagger$ \\
\hline \multicolumn{6}{|l|}{ Higher-income: } \\
\hline Bahamas & 1818 & 48.5 & 1345 & & 2021 \\
\hline Barbados & 1198 & 31.7 & 928 & 50.8 & 1487 \\
\hline Chile & 1717 & 1354.9 & 987 & 2054.2 & 1496 \\
\hline Puerto Rico* & & 1009.1 & 2764 & 1806.6 & 4949 \\
\hline Trinidad \& Tobago & 1822 & 190.2 & 1356 & 289.4 & 2063 \\
\hline Uruguay & 1792 & 97.4 & 618 & 129.4 & 821 \\
\hline Sub-total & $1669 \dagger$ & 2731.8 & $1333 \dagger$ & 4403.3 & 2140 \\
\hline Total & $1063 \dagger$ & 43701.5 & $1088 \dagger$ & 64685.3 & $1818 \dagger$ \\
\hline
\end{tabular}

* National Health Expenditures (NHE) figure for Puerto Rico was not available.

$\dagger$ Average.

The total cost of diabetes in LAC was estimated to be between US\$ 103 and US $\$ 124$ billion in 2015. The highest cost was estimated for Brazil between US\$ 37 and US $\$ 43$ billion while the lowest cost was estimated for Grenada between US\$ 39 and US\$ 42 million (Table 7).

Table 8 presents a summary of detailed explanations of all components, sources of the data, estimations and the corresponding cost result.

\section{DISCUSSION}

The estimated number of people with DM in countries of LAC soared from 15 million in 2000 to 41 million in 2015, - a 2.7-fold increase in 15 years. In 2015, the economic burden of diabetes was estimated to be between US\$ 103 and US\$ 124 billion, which represents a 6 to 7 -fold increase in the total cost, 4 to 6-fold increase in direct medical, as well as a 8-fold increase in indirect costs compared to the previously estimated costs for 2000 [1].

Data presented here tends to be conservative and may underestimate the real cost of diabetes. This analysis included the best information available, however, there is a lack of information on the cost of proce- 
Table 7. Direct, indirect and total cost of diabetes mellitus (DM) by country and GDP, Latin America and the Caribbean, 2015

\begin{tabular}{|c|c|c|c|c|c|}
\hline \multirow[t]{2}{*}{ LOWER-MIDDLE INCOME: } & \multirow{2}{*}{$\begin{array}{l}\text { INDIRECT COSTS } \\
\left(\text { USS } \times 10^{6}\right)\end{array}$} & \multicolumn{2}{|c|}{ S1 (Lower) } & \multicolumn{2}{|c|}{ S2 (HighER) } \\
\hline & & $\begin{array}{c}\text { Direct costs } \\
\left(\text { US } \$ \times 10^{6}\right)\end{array}$ & $\begin{array}{l}\text { Total costs } \\
\left(\text { US } \$ \times 10^{6}\right)\end{array}$ & $\begin{array}{c}\text { Direct costs } \\
\left(\text { US } \$ \times 10^{6}\right)\end{array}$ & $\begin{array}{l}\text { Total costs } \\
\left(\text { US } \$ \times 10^{6}\right)\end{array}$ \\
\hline Bolivia & 358 & 264 & 622 & 485 & 843 \\
\hline El Salvador & 245 & 355 & 601 & 667 & 912 \\
\hline Guatemala & 523 & 1059 & 1582 & 1948 & 2471 \\
\hline Guyana & 44 & 28 & 72 & 46 & 90 \\
\hline Honduras & 180 & 467 & 648 & 859 & 1039 \\
\hline Nicaragua & 110 & 307 & 417 & 518 & 628 \\
\hline Paraguay & 229 & 305 & 534 & 546 & 774 \\
\hline Sub-total & 1690 & 2786 & 4476 & 5068 & 6757 \\
\hline \multicolumn{6}{|c|}{ Upper-middle income: } \\
\hline Argentina & 1740 & 1771 & 3511 & 3057 & 4796 \\
\hline Belize & 21 & 22 & 42 & 33 & 54 \\
\hline Brazil & 19052 & 18271 & 37323 & 24605 & 43656 \\
\hline Colombia & 2805 & 3087 & 5892 & 5527 & 8331 \\
\hline Costa Rica & 286 & 298 & 584 & 527 & 814 \\
\hline Cuba & 1590 & 581 & 2170 & 956 & 2545 \\
\hline Dominican Republic & 464 & 328 & 792 & 481 & 946 \\
\hline Ecuador & 742 & 1187 & 1929 & 1795 & 2537 \\
\hline Grenada & 35 & 4 & 39 & 7 & 42 \\
\hline Jamaica & 239 & 328 & 567 & 526 & 765 \\
\hline Mexico & 17240 & 10835 & 28075 & 14423 & 31663 \\
\hline Panama & 344 & 364 & 708 & 608 & 952 \\
\hline Peru & 1209 & 571 & 1780 & 1021 & 2230 \\
\hline Saint Lucia & 11 & 9 & 20 & 14 & 26 \\
\hline Suriname & 51 & 27 & 78 & 43 & 94 \\
\hline Venezuela & 6062 & 1800 & 7862 & 2891 & 8953 \\
\hline Sub-total & 51890 & 39483 & 91373 & 56514 & 108404 \\
\hline \multicolumn{6}{|l|}{ Higher-income: } \\
\hline Bahamas & 70 & 50 & 120 & 75 & 145 \\
\hline Barbados & 40 & 33 & 73 & 52 & 92 \\
\hline Chile & 2224 & 1430 & 3654 & 2129 & 4353 \\
\hline Puerto Rico & 440 & 1035 & 1475 & 1832 & 2272 \\
\hline Trinidad \& Tobago & 315 & 199 & 514 & 298 & 613 \\
\hline Uruguay & 512 & 105 & 617 & 137 & 649 \\
\hline Sub-total & 3601 & 2852 & 6453 & 4523 & 8125 \\
\hline Total & 57181 & 45121 & 102302 & 66105 & 123286 \\
\hline
\end{tabular}

dures and services. Therefore, these costs were not included in the amount attributed to consultations, emergency visits, hospitalizations or visits to ophthalmologists. On the other hand the frequency of testing and consultations, may vary widely among countries. The cost of medications and care might have variations depending on purchasing capacity and government policies. Because of that, two different scenarios were prepared. For S1 and S2, lower and higher coverage for medication, testing and service as well as cost for treating diabetes complications respectively were assumed. These different estimates resulted in very different direct cost estimates for scenario 1 and scenario 2 . Keeping constant indirect costs, the observed variation of the total cost of diabetes reflects the sensitivity to different assumption for each component such as medication and care for complications. Scenario 2 is 31 percent costlier than scenario 1 . Sensitivity is also clearly related to the cost of medication. For example If all other cost assumptions are kept as established for $\mathrm{S} 1$ and $\mathrm{S} 2$, and the cost of insulin is reduced to US\$ 4.20 per vial, it would result in cutting direct cost in 50\% and the per capita cost of diabetes care by 35\% (data not shown).

The proportion of direct and indirect cost was 44\% and 56\% for S2 and 54\% and 46\% for S1 respectively. These variations are driven by the difference in access to care and the cost of complications assumed for S1 and S2. These results are consistent with previous research, for example, an African study calculated direct medical cost at 43\% and indirect cost at 56\% [25] similar to our proportion in S1; while the ADA estimates indicated a higher proportion of direct cost at $72 \%$ and lower proportion of indirect cost 
Table 8. The cost of diabetes in Latin American and the Caribbean in 2015

INDIRECT COST SOURGE

Number of people with DM

Permanent disability Number of persons with diabetes with permanent disability: 1043128 . Estimated by multiplying the economically active diabetes population in each country by the proportion of people with permanent disability by age and gender. These proportions were calculated by estimating the proportion of people receiving benefits due to diabetes by age and gender in Brazil, adjusted by diabetes duration and the prevalence of chronic disabling diabetes complication in the Chilean database (those with amputations, Chronic Kidney Disease (CKD), blindness, cerebrovascular disease and infarctions), approximate $33.5 \%$ of the total population with diabetes.

Cost calculated by multiplying years lost to disability by annual country GNP per capita. Cost of permanent disability in one year.

Temporary disability The estimated number of person with diabetes in the labor force was estimated by discounting the unemployed (according to each country unemployment rate published by the World Bank) among those in working ages (20-64 y of age): 31872702 . Number of sick days related to diabetes 10.5 days per person per year as per results of the ViCen survey.

Number of years lost due sick days: 858154 . Cost calculated by multiplying years of productivity lost by 13391123563 GNP per capita.

Mortality Estimated number of all causes deaths: 1386513.

Calculated by the Population Attributable Fraction using OR obtained from the BES study.

Estimated number of deaths among those with diabetes: 318102 (173532-461 789).

Estimated number of years lost due to premature mortality: 2074633 . Years lost before age 65 y with a 3\%

discount rate. Cost calculated by multiplying years lost to premature mortality in each country by annual GNP per capita.

Indirect cost total

Direct cost

Insulin

Scenario 1: Proportion of people with diabetes using insulin: 10\%.

Insulin consumption per year: 10000 units per person

Number of insulin users: 4053699 . Cost of insulin in each country obtained from the PAHO database.

66995221314

Scenario 2: Proportion of people with diabetes using insulin: $20 \%$.

Insulin consumption per year: 10000 units per person

Number of insulin users: 6914458. Cost of insulin in each country obtained from the PAHO database.

11611301234

Oral medication Scenario 1: Oral medication consumption per year: 1500 tablets of Metformin. Users 50\% of the diabetes population

Oral medication users: 19748788. Cost of metformin in each country obtained from the PAHO database.

44028574000 Scenario 2: Oral medication consumption per year: 1500 tablets of Metformin. Users 80\% of the diabetes population

Oral medication users: 33572940 . Cost of metformin in each country obtained from the PAHO database.

Consultations Scenario 1: Estimated that $50 \%$ of people were followed by health services.

6848575800

Estimated number of consultations related to DM per year for people with diabetes: 105312278. Number of consultations per inhabitant from PAHO's basic indicators. The ViCen survey indicated that people with diabetes had 3.5 more visits than those without diabetes. Visit for general causes were subtracted. The number of consultations due to diabetes was multiplied by the estimated number of people with diabetes in each country. The cost of consultations per country was obtained from the PAHO database.

Scenario 2: Estimated that $85 \%$ of people were followed by health services. Estimated number of consultations related to DM per year for people with diabetes: 162755 . Number of consultations per inhabitant from PAHO's basic indicators. The ViCen survey indicated that people with diabetes had 3.5 more visits than those without diabetes. Visit for general causes were subtracted. The number of consultations due to diabetes was multiplied by the estimated number of people with diabetes in each country. The cost of consultations per country was obtained from the PAHO database.

Hospitalizations Scenario 1-2: Total number of DM hospitalizations per year for people with diabetes: 18293614. The ViCen survey indicated that people with diabetes were hospitalized 7 times and hospital stay was $1.9 \mathrm{~d}$ longer than those without diabetes. Number of hospital discharges per inhabitant for the general population from the PAHO basic indicator database was used to estimate the excess hospital days due to diabetes in each country. Cost of one hospital day in each country obtained from the PAHO database.

Emergency visits Scenario 1-2: Total number of DM emergency visit per year for people with diabetes: 95625710 ; estimated number of diabetes related emergency visits 95626 . The ViCen survey indicated that people with diabetes had 1.4 more emergency visit than those without diabetes.

Number of emergency visits per inhabitant for the general population from the PAHO basic indicator database was used to estimate the excess emergency visits due to diabetes in each country. Only visits assumed to be related to diabetes were included in cost calculation. Cost of an emergency visit in each country obtained from the PAHO database.

Test and laboratory Scenario 1: Includes the cost of one Alc, one lipid profile, one albuminuria test, one EKG, and one X Ray exams for $50 \%$ of the diabetes population of each country. Cost of items in each country obtained from the PAHO database.

Scenario 2: Includes the cost of three Alc, one lipid profile, one albuminuria test, one EKG, and one X Ray for $50 \%$ of the diabetes population of each country. Cost of items in each country obtained from the PAHO database.

5067964481

6805773280

10333828105

11058606746

1379772482

2858452553 
Table 8. Continued

\begin{tabular}{|c|c|c|}
\hline InDIRECT COST & Source & Cost (US\$) \\
\hline \multirow[t]{2}{*}{$\begin{array}{l}\text { Excess cost of } \\
\text { complications }\end{array}$} & $\begin{array}{l}\text { Scenario 1: The age-and-gender weighted probability of diabetes complications (cardiovascular disease } \\
0.11 \text {, nephropathy } 0.06 \text {, neuropathy } 0.09 \text {, peripheral vascular disease } 0.06 \text { and retinopathy } 0.12 \text { ) was ob- } \\
\text { tained from the Chilean QUALIDIAB database. The excess cost of each diabetes complication was applied } \\
\text { to the cost of uncomplicated cases following results from the Mexican NIH database (excess cost of compli- } \\
\text { cations: neuropathy 1.08; peripheral vascular disease } 11.06 \text {; cardiovascular disease } 1.23 \text {; nephropathy } 11.76 \text {; } \\
\text { retinopathy 1.09) }\end{array}$ & 16256804668 \\
\hline & $\begin{array}{l}\text { Scenario 2: The age-and-gender weighted probability of diabetes complications (cardiovascular disease } \\
0.11 \text {, nephropathy } 0.06 \text {, neuropathy } 0.09 \text {, peripheral vascular disease } 0.06 \text { and retinopathy } 0.12 \text { ) was ob- } \\
\text { tained from the Chilean QUALIDIAB database. The excess cost of each diabetes complication was applied } \\
\text { to the cost of uncomplicated cases following results from the Mexican NIH database (excess cost of compli- } \\
\text { cations: neuropathy } 1.58 \text {; peripheral vascular disease } 1.81 \text {; cardiovascular disease } 1.86 \text {; nephropathy } 2.96 \text {; } \\
\text { retinopathy 1.86) }\end{array}$ & 26587999416 \\
\hline \multirow[t]{2}{*}{ Direct cost total } & Scenario 1 & 45120771799 \\
\hline & Scenario 2 & 66104537136 \\
\hline \multirow[t]{2}{*}{ Total Cost of DM } & Scenario 1 & 102301795665 \\
\hline & Scenario 2 & 123285561002 \\
\hline
\end{tabular}

$\mathrm{DM}$ - diabetes mellitus, y - year

at 28\% [26] because of the well-known high cost of many medical services and procedures in the United States. The Brazilian study estimated the direct and indirect cost at $63 \%$ and 37\%, respectively [17]. But the difference in the proportion of direct and indirect cost can be also due to the inclusion of different items in the study, real differences in the cost of procedures and medications, as well as differences in access to care.

On average, health care cost was estimated at US\$ 1088-1819 per capita with wide ranges from US\$ 4979 (S2) in Puerto Rico to US\$ 540 (S1) in Guyana. The ADA [26] study estimated the per capita cost of diabetes at US\$7900 [21] in the US, which was much higher than the cost reported in this study for LAC. In Africa, this figure varied from US\$2144.3 to US\$ 11431.6 depending on the country's Gross National Income [25]. Interestingly, there were substantial differences in the items included in the North American, African and this current LAC study. The ADA [26] and the African [25] studies both included diabetes supplies, in addition the ADA [26] study included home care; those items were not included in the present study.

Our results for per capita direct cost was consistent to previous research in the region such as those published for Brazil [17], Argentina [27], and the South-Central America (SACA) Region [27]. The Brazilian study estimated the direct per capita cost to be US\$ 1334 [17], which is close to the US\$ 1227-1672 we estimated for Brazilian persons with diabetes. The Argentine study [27] estimated the quarterly direct per capita cost of DM in a social security institution at US\$904.60 and US\$1841.80 Argentine pesos for DM cases with and without chronic complications, respectively. These figures translate into US\$ 1796.82 (without chronic complications) and US\$2037.89 (with chronic complications) per year. These estimations are closed to estimations reported in this study for Argentina (US\$ 1010-1773) [27]. De Rocha Fernandes et al. [28] calculated health care cost for the IDF-SACA region between US\$1155 and US\$2024 for 2014, which overlap to our results for the same region of IDF at US\$ 1136-1711 (data not shown).

A big gap was observed between NHE and the cost of diabetes care especially among lower income countries. This gap, as suggested by Arredondo et al [29] in Mexico, may result in out of pocket expenses in some cases [25] or the avoidance of necessary services because of economic constrains in others.

The total economic burden of diabetes among countries is highly driven by the size of the population, baring higher cost for countries with bigger population size such as Brazil, Mexico and Argentina. Per capita direct cost however, depends more on national prices of goods and services. Some of them have proven to be highly variable. The best example is the price of a vial of insulin, which price varied from US\$ 78 in Puerto Rico to US\$ 1.25 in Cuba (average price US\$20). The Pan American Health Organization Strategy Fund (PAHO-SF) offers high quality medicine at affordable prices to countries of the Americas [30]. For example, a vial of $100 \mathrm{ml}$ of high quality insulin is offered by PAHO-SF at US\$ 4.20 to Member States. Running our analysis replacing country specific prices for insulin and oral medication with PAHO-SF's prices (plus 15\%) in our data, resulted in cutting direct cost in 50\% and the per capita cost of diabetes care by 35\% (data not shown). 
Prevalence estimates in this paper are based on epidemiological studies on the frequency of DM prepared for the Diabetes Atlas [2]. It was assumed that 55\% (S1) or 85\% (S2) of the total number of cases received care; however, this proportion may vary widely from country to country. Furthermore, the proportion of cases receiving treatment may vary according to access to care, patient's educational level, and the capacity of the health system.

Major limitations of this study include the lack of information on many issues which were replaced by assumptions that in many cases cannot be confirmed. That is the case of the proportion of cases receiving services, the prevalence of diabetes chronic complications (approximations are based on one local study), and the proportion of people with permanent or temporary disability. In every case the best information available was used to generate estimates for the missing information. The results of this study were consistent when compared, as discussed previously, to small number of research reports available in the medical literature on the subject from Argentina [27], Brazil [17] and the SACA Region [28]. It is, however, suggested that these results be considered with caution, since inaccuracy may occur when making similar assumption for many countries with different health and financial systems. All cost components were adjusted to the age-and-sex population estimates for each country, except for the proportion of cases receiving treatment or under care. The latest was not possible because of the lack of information on these issues. Finally, we used in our estimates commercial prices for services and medication for each country. This was done so because prices for government provided goods and services were not available in every country. It may be possible that these services and medications are available at lower subsidized prices in some of the countries. Prices of medication and services for each country depended on information provided by a wide variety of collaborators including government officials, member of diabetes or professional associations, health providers and other volunteers. Biases introduced by the observers could not be controlled in any possible way.

While providing comparable estimates of the cost of diabetes among countries, this paper alerts public health officials of the growing burden of DM in LAC. It provides arguments to reinforce needs to strengthen public policies that promotes health and diabetes prevention, such as those that discourage the consumption of junk food or sugary drinks and promote physical activity; as well as those focused on increasing access to diabetes care and supplies.

DM represents a major public health problem in LAC. Middle and low-income countries face a major challenge that not only affects their health system organization and financing, but also their economic growth. Buying medication from PAHO-SF instead of paying market prices may reduce the burden that diabetes care represents to countries and individuals. As the prevalence of DM is expected to increase in the near future, so will its toll on individuals, families and society as a whole.

\section{CONCLUSIONS}

The high economic burden of diabetes showed here has strong implications for the health systems and the economic grow of the nations of LAC. This burden is related to direct medical care but also to indirect cost caused by loss of productivity due to premature death and disability. Multi-sector public policies could contribute to curve this treat on the long term.

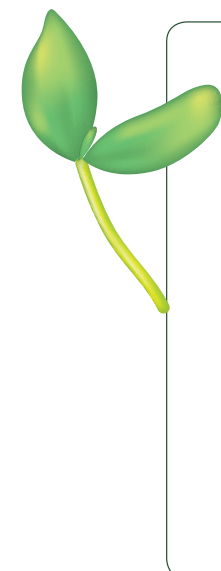

Acknowledgements: The following individuals contributed with country-based data: Maltie Algoe, Dr Arias, Raul Aviles, Noël Barengo, Adelina Barrantes, Aracely Basurto Calderon, Gilda Benitez, Oscar Boggio, Imperia Brajkovich, Felicia Cańete, Roberto del Aguila, Eizabeth Duarte, Felix Escańo, Tomiris Estepan, Manodj Hindori, Nestor Alberto Huiman, Fadlo Fraige filho, Sebastian Laspiur, Olga Graciela López Mena, Esha Marhé, Enrique Medina Sandino, Viginia Molina, Carlos Olimpo Mendivil, Eduardo Palacios, Oris Ruiz, Gerardo Solano, Maria Suniaga, Emilce Herrera, Josue Hernandez.

Funding: None.

Authorship declaration: $\mathrm{AB}, \mathrm{AG}$ and $\mathrm{AA}$ researched data and wrote and edited the manuscript. AB, AA, JS and $A Q$ researched data, performed statistical analysis, and wrote and edited the manuscript. AB, AA, AG, JS and AQ researched data and reviewed and edited the manuscript.

Competing interests: The authors have completed the Unified Competing Interest form at www.icmje.org/ coi_disclosure.pdf (available on request from the corresponding author) and declare no conflict of interest. 
1 Barceló A, Aedo C, Rajpathak S, Robles S. The cost of diabetes in Latin America and the Caribbean. Bull World Health Organ. 2003;81:19-27. http://www.ncbi.nlm.nih.gov/pmc/articles/PMC2572319/pdf/12640472.pdf. Medline:12640472

2 International Diabetes Federation. Diabetes Atlas. SeventhE5Seventh Edition, 2015. ISBN: 978-2-930229-81-22. International Diabetes Federation, 2013. Available: www.idf.org/diabetesatlas. Accessed: 11 October 2015.

3 The World Health Organization. Assessing National Capacity for the Prevention and Control of Non-communicable Diseases, 2013. Report of the Americas Region, Washington D.C. December 2013.

4 Gobierno de Chile. Ministerio de Salud. Universidad Alberto Hurtado. Encuesta Nacional de Salud ENS 2009-2010. V Resultados. Santiago de Chile 2012. http://web.minsal.cl/portal/url/item/bcb03d7bc28b64dfe040010165012d23.pdf Accessed: 21 July 2015.

5 Gagliardino JJ, Kleinebreil L, Colagiuri S, Flack J, Caporale JE, Siri F, et al. Comparison of clinical-metabolic monitoring and outcomes and coronary risk status in people with Type 2 diabetes from Australia, France and Latin America. Diabetes Res Clin Pract. 2010;88:7-13. Medline:20153542 doi:10.1016/j.diabres.2009.12.024

6 Lopez Stewart G, Tambascia M, Rosas Guzmán J, Etchegoyen F, Ortega Carrión J, Artemenko S. Control of Type 2 diabetes mellitus among general practitioners in nine countries of Latin America. Rev Panam Salud Publica. 2007;22:12-20. Medline:17931483 doi:10.1590/S1020-49892007000600002

7 Pan American Health Organization. The Central America Diabetes Initiative (CAMDI): Survey of Diabetes, Hypertension and Chronic Disease Risk Factors. Belize, San José, San Salvador, Guatemala City, Managua and Tegucigalpa. Washington, D.C.: PAHO, ( ) 2011. ISBN: 978-92-75-13098-8. Available: http://www.paho.org/hq/index.php?gid=16710\&option=com docman\&task=doc_view. Accessed: 21 July 2015.

8 Commendatore V, Dieuzeide G, Faingold C, Fuente G, Lujan D, Aschner P, et al. Registry of people with diabetes in three Latin American countries: a suitable approach to evaluate the quality of health care provided to people with Type 2 diabetes. Int J Clin Pract. 2013;67:1261-6. Medline:24246207 doi:10.1111/ijcp.12208

9 Mudaliar U, Kim WC, Kirk K, Rouse C, Narayan KM, Ali M. Are recommended standards for diabetes care met in Central and South America? A systematic review. Diabetes Res Clin Pract. 2013;100:306-29. Medline:23375230 doi:10.1016/j. diabres.2013.01.010

10 Rice DP. Estimating the cost of illness. Health Economics Series No. 6, PHS No. 947-6. US Government Printing Office, Washington (DC); 1966

11 United Nations. World Population Prospects (2009).

12 The World Bank. World Development Indicators. Available: http://data.worldbank.org/data-catalog/world-developmentindicators. Accessed: 6 April 2015.

13 The World Bank. New Country Classification. Available: http://data.worldbank.org/news/new-country-classifications. Accessed: 17 March 2015

14 Pan American Health Organization. Basic Indicator Database. Washington DC 20014.

15 Pan American Health Organization. National Capacity for the Management of Chronic Diseases in Latin America \& the Caribbean. Washington DC, 2010.

16 Pan American Health Organization. The Use of Health Resources and Diabetes Complications. The ViCen Survey, 2014.

17 Bahia LR, Araujo DV, Schaan BD, Dib SA, Negrato CA, Leăo MP, et al. The costs of Type 2 diabetes mellitus outpatient care in the Brazilian public health system. Value Health. 2011;14(5 Suppl 1):S137-40. Medline:21839888 doi:10.1016/j. jval.2011.05.009

18 Escobar MC. Ministerio de Salud de Chile. Evaluación de la calidad de la atención de pacientes diabéticos controlados en establecimientos del Sistema Nacional de Servicios de Salud Resultados: Plan de Reforzamiento QUALIDIAB-Chile 2011. Santiago de Chile, 2012. Available: http://www.redcronicas.cl/wrdprss_minsal/wp-content/uploads/2014/04/Plande-Reforzamiento-QUALIDIAB-Chile-2011-Dra-Escobar1.pdf. Accessed: 11 October 2015.

19 Arredondo A, Aviles R. Costos y consecuencias financieras del cambio en el perfil epidemiológico en enfermedades crónicas en México. Technical Report. 1999-2014. Update of costs and probabilistic models, June 2014.

20 Hennis A, Wu SY, Nemesure B, Li X, Leske MC; Barbados Eye Study Group. Diabetes in a Caribbean population: epidemiological profile and implications. Int J Epidemiol. 2002;31:234-9. Medline:11914326 doi:10.1093/ije/31.1.234

21 Phillips M, Salmerón J. Diabetes in Mexico - a serious and growing problem. World Health Stat Q. 1992;45:338-46. Medline:1299074

22 Ministerio de Salud. Cuba. III Encuesta Nacional de Factores de Riesgo de y Actividades Preventivas de Enfermedades No Transmisibles. Editorial Ciencias Médicas. ISBN 978-959-212-894-1. Habana, Cuba, 2014.

23 Gomes de Moura AA, Freese de Carvalho E, Carvalho da Silva NJ. Impacts of non-transmissible chronic diseases on social security benefits. Cięncia \& Saúde Coletiva 2007;12(6):1661-1672. Available: http://www.scielo.br/pdf/csc/v12n6/ v12n6a25.pdf.Accesse: 23 April 2017.

24 Governo do Brasil. Ministerio de Previdęncia Social. Anuario Estadístico da Previdencia Social 2015. Available: http:// www.previdencia.gov.br/wp-content/uploads/2015/08/AEPS-2015-FINAL.pdf. Accessed: 23 May 2017.

25 Kirigia MJ, Sambo HB, Sambo LG, Barry SP. Economic burden of diabetes mellitus in the WHO African Region. BMC Int Health Hum Rights. 2009;9. Medline:19335903 doi:10.1186/1472-698X-9-6.

26 American Diabetes Association. Economic Cost of Diabetes in the US in 2012. Diabetes Care. 2013;36:1033-46. Medline:23468086 doi:10.2337/dc12-2625

27 Elgart JF, Asteazaran S, De La Fuente JL, Camillucci C, Brown JB, Gagliardino JJ. Direct and indirect costs associated to Type 2 diabetes and its complications measured in a social security institution of Argentina. Int J Public Health. 2014;59:851-7. Medline:25189732 doi:10.1007/s00038-014-0604-4 
28 da Rocha Fernandes J, Ogurtsova K, Linnenkamp U, Guariguata L, Seuring T, Zhang P, et al. IDF Diabetes Atlas estimates of 2014 global health expenditure on diabetes. Diabetes Res Clin Pract. 2016;117:48-54. Medline:27329022 doi:10.1016/j. diabres.2016.04.016

29 Arredondo A. Type 2 diabetes and health care costs in Latin America: exploring the need for greater preventive medicine. BMC Med. 2014;12:136. Medline:25266304 doi:10.1186/s12916-014-0136-z

30 Pan American Health Organization. The Pan American Health Organization Strategy Fund. Available: http://www.paho. org/hq/index.php?option=com_content\&view=article\&id=12163\%3Apaho-strategic-fund $\&$ catid=8775\%3Aabout\&It emid=42005\&lang=en. Accessed: 26 May 2017. 